\title{
BREAKING THE SILENCE: Achieving a Positive Campus Climate for Diversity from the Staff Perspective
}

\author{
Matthew J. Mayhew, ${ }^{\star} \ddagger$ Heidi E. Grunwald, ${ }^{* *}$ and Eric L. Dey†
}

The purpose of this paper is to identify factors that create a positive climate for diversity and to demonstrate how these factors predict outcomes related to achieving a positive campus climate for diversity. Based on survey data collected from 437 staff members employed at a large, public, predominantly White university in the Midwest, results suggest that the institution's ability to achieve a positive climate for diversity reflects not only the personal characteristics of the staff member (race, gender, education level, and age) but also their perceptions of their immediate work environment. Implications are discussed.

KEY WORDS: diversity; climate; staff; administration; quantitative; higher education; college personnel.

Recent Supreme Court rulings associated with the use of affirmative action in college admissions processes has renewed national interest in issues related to diversity on campus. The importance, value, and contribution of diversity, though, is not limited to students or faculty, but to those who work in staff on college campuses as well as other organizational settings (Cox, 1993, 2001; Cox and Blake, 1991; Fortune 500 Companies, 2003; General Motors Corporation, 2003). As a result of the recognized importance of diversity, campus leaders continue to scramble to identify the variety of factors that contribute to creating a positive climate for diversity on campus (Hurtado, Milem, ClaytonPedersen, and Allen, 1998).

\footnotetext{
*University of North Carolina, Wilmington.

**Temple University.

$\dagger$ University of Michigan.

\$Address correspondence to: Matthew J. Mayhew, Office of Student Life Assessment, University of North Carolina, Wilmington, 601 S. College Road, \#5983, Wilmington, NC 28403. E-mail: mayhewm@uncw.edu
} 
Part of the process involved with identifying and making sense of the factors that contribute to creating a positive climate for diversity on campus involves soliciting information from all members of the campus community. As Hurtado and Dey (1997) note, a meaningful assessment effort designed to measure a campus' climate for diversity should "ensure that multiple perspectives from the campus are represented, including individuals who play different roles on campus (faculty, students, staff) as well as multiple campus communities that may be based on race, gender, disability, or field of study" (p. 422). The rationale is that perceptions of the campus community's ability to achieve a positive climate for diversity are likely to vary between faculty, students, and staff and between people with different personal and professional characteristics.

However, the majority of research designed to provide information on the campus community's ability to achieve a positive climate for diversity focuses almost entirely on faculty and student perceptions of, beliefs about, and experiences with diversity on campus (Chang, 2002; Hurtado, 2001; Maruyama, Moreno, Gudeman, Harvey, and Marin, 2000; Milem, 2001). To date, no empirical studies have examined the factors that predict staff members' perceptions of their campus community's ability to achieve a positive climate for diversity.

\section{THEORETICAL OVERVIEW}

Organizational climate is a term that organizational theorists use to describe "the current common patterns of important dimensions of organizational life or its members' perceptions of and attitudes towards those dimensions" (Peterson and Spencer, 1990, p. 173). The current study is interested in dimensions of the campus climate that are related to issues of diversity as perceived and experienced by university staff members.

Hurtado et al. (1998) position these dimensions in a four-part framework that describes an institution's diversity climate. These include a campus' historical legacy of inclusions or exclusion of various racial or ethnic groups, its structural diversity (i.e., the numerical and proportional representation of diverse groups on campus), its psychological climate (i.e., perceptions, attitudes, and beliefs about diversity) and its behavioral climate (i.e., how different racial and ethnic groups interact on campus). The extent to which these four dimensions make diverse university constituents feel comfortable as welcome and belonging members of the campus community reflects one way a campus can achieve a positive climate for diversity. This is what we mean by the campus community's ability to achieve a "positive climate for diversity." 
For the purposes of this study, we have concentrated on three dimensions of the institution's climate for diversity. The constructs developed for this study reflect the structural diversity of staffs' departments, their perceptions of their departmental and institutional climates and commitments to diversity, and their diversity-related experiences on campus, including their positive interactions with diverse others. We realize that these constructs do not capture the essence of what Hurtado et al. (1998) would describe as essential for understanding the complexity of an institution's diversity climate; however, they are useful for organizing variables in ways that readily enable researchers to understand how staffs' perceptions vary across departmental and institutional contexts as well as across staff characteristics (e.g., race and gender) and diversityrelated experiences.

Although research has addressed different elements of an institution's climate that contributes to our understanding of diversity-related issues (Chang, 2002; Hurtado, 2001; Hurtado and Dey, 1997; Hurtado et al., 1998; Maruyama et al., 2000; Milem, 2001), none has investigated what factors influence staff perceptions of their community as having achieved a positive climate for diversity - making this study a distinctive contribution to the literature on diversity.

\section{LITERATURE REVIEW}

For an organization to be successful in initiating a system-wide reform effort, it needs to procure and maintain support from all stakeholders within the organization (Bolman and Deal, 1997). For institutional planning and management teams, effective reform-based initiatives require equal "buy-in" from faculty, administrators, and staff (Birnbaum, 1988). Despite the charge to include the voices of staff members in instituting system-wide initiatives, there remains a dearth of empirical studies designed to explore staff members' perceptions of diversity-related issues on campus. As a result, in some cases, we review literature on faculty perceptions of the campus climate for diversity as a proxy for staff perceptions. We end the literature review with the research questions developed for this study.

A handful of information gathering efforts have been attempted to address the role of staff members in creating and sustaining diversityrelated initiatives (Association of American Colleges and Universities, 1998; Baker, 1999; Berkeley, 1997; Growe, Schmersahl, Perry, and Henry, 2001; Horton, 2000; Howard-Hamilton, Phelps, and Torres, 1998; Kellogg, 1999; Sanchez, 1995; Walters, 2002). However, few of these efforts were designed to capture staff members' perceptions of 
their campus community's success in achieving a positive climate for diversity. Instead, these studies were designed to provide descriptive information about the roles of staff in supporting diversity-related initiatives. For example, Walters (2002) performed a case study of Olivet College and described the role of staff, faculty, and students in successfully realizing a diversity initiative that incorporated an institution-wide commitment to multiculturalism and minority student success. The product of this analysis was an action plan designed to communicate the challenges of implementing diversity-related initiatives on campus. While efforts like this are useful in understanding how staff members contribute to the success of diversity-related initiatives, they provide little information about staff members' perceptions of and experiences with diversity.

One study was designed to capture staff members' experiences with diversity on campus. Marcus (2000) performed a case study at a community college to examine how a diverse staff experienced the work place. He examined the inter-group relations among administrators at a college that had been successful in hiring women and people of color at all levels of its administrative staff and found that women and staff of color responded differently than men and white staff to questions involving organizational politics and culture, quality of supervision, and frequencies in mentorship opportunities. Although findings from this study cannot be generalized, they underscore the importance of understanding how staff of color and women staff may perceive their institution's climate for diversity differently than whites and male staff. These findings are supported by Hurtado et al.'s (1998) assertion that "racially and ethnically diverse administrators, students, and faculty tend to view the campus climate differently" (p. 289). For this reason, we include a series of staff demographic (gender, race, age, education) and professional (length of employment, position classification, and department) variables in our analysis to shed light on how perceptions of a campus' climate for diversity varies across staff characteristics.

No empirical studies have examined the role of department and institutional contexts on influencing staff perceptions of their institution's climate for diversity. However, there are some studies that examined how faculty perceptions and behaviors are influenced by their perceptions of both their department (Lindholm, 2003; Peterson, 1976; Mayhew and Grunwald, in press) and of their institution (Maruyama et al., 2000; Milem, 2001). At the department level, Peterson (1976) found that faculty members tend to relate to their institutions most extensively through their academic departments. At the institutional level, Milem (2001) found that faculty members who perceived an emphasis of 
institutional commitments to civic responsibility were more likely to integrate diversity-related materials into their curriculum.

In a study that examined how faculty's perceptions of both their department and their institutions influenced their incorporation of diversity-related course learning into their curricula, Mayhew and Grunwald (in press) found that faculty decisions to incorporate diversity-related material into their courses were based on their perceptions of their departments' commitment to support diversity-related initiatives, not on their perceptions of the institutions' commitment to support diversity-related initiatives. Collectively, these findings emphasize the importance of examining the effects of department and institutional contexts for their respective potential to exert influence over staffs' perceptions of the institution's success in achieving a positive climate for diversity. For this reason, we chose a blocked, hierarchical approach for entering variables into our model; such an approach enables us to isolate the effects of the department from those of the institution on the campus community's ability to achieve a positive climate for diversity.

\section{Research Questions}

The overarching research question is: what factors influence staff perceptions of their campus community as having achieved a positive climate for diversity? More specifically, we seek to answer the following sub-questions:

1. How do staff members' perceptions of their campus community as having achieved a positive climate for diversity differ as a function of their demographic characteristics? More specifically, how do these perceptions differ as a function of their gender and race?

2. What role do staff professional characteristics, the structural diversity of the department, staff experiences with diversity on campus, staff perceptions of their departments' climate for diversity, and staff perceptions of their institution's commitment to diversity play in influencing these perceptions?

a. How do staff members' professional characteristics influence their perceptions of the campus community as having achieved a positive climate for diversity?

b. How does the structural diversity of staff members' departments contribute to their perceptions of the campus community's success in achieving a positive climate for diversity? 
c. How does the psychological climate of staff members' departments contribute to their perceptions of the campus community's success in achieving a positive climate for diversity?

d. How do staff members' perceptions of their institution's commitment to diversity influence their perceptions of their campus community's ability to achieve a positive climate for diversity?

e. How do staff members' experiences with diversity contribute to their perceptions of their campus community as having achieving a positive climate for diversity?

\section{University Context}

This university is a predominantly White, public university in the Midwest. Historically, this university acknowledges struggling with creating an environment that welcomes and appreciates diversity. The university recently instituted a comprehensive university plan for strengthening its diversification efforts; this plan was distributed to faculty and staff in the fall of 1998. The plan institutionalized diversity initiatives, including the recruitment of minority faculty and students, the creation co-curricular programs and events designed to increase diversity awareness, and the integration diversity-related course learning into the existing curriculum.

Apparently, these initiatives have been effective. Over the course of the past 6 years, multicultural student enrollment has increased $26 \%$. Multicultural faculty recruitment efforts follow similar patterns: from 61 minority faculty members in 1992 to 97 in 2002. Although no such figures are reported for staff, the university has created many new multicultural programs (e.g., providing housing for two historically African-American fraternities and two African-American sororities) and organizations (e.g., the Center for Black Culture and Learning); each of these efforts are partially managed and staffed by diverse staff. While the university has not yet reached its goals with regard to increasing the structural diversity of the campus, campus administrators continue to brainstorm new programs and initiatives with the intention of creating a more welcoming and diverse campus community.

\section{DATA AND METHODOLOGY}

\section{Sample}

In January 2002, a sample of 1029 staff members was randomly selected from a population of 2202 at a large, Midwestern, predominantly 
White, public university. Of the 2202 staff solicited for participation in the study, 437 returned useable surveys; this yielded a response rate of $42.5 \%$.

Female staff represents $65 \%$ of the surveyed sample. The sample is predominantly White $(83 \%)$; staff of color represent $17 \%$ of the sample (African American $=10.7 \%$; Asian $/$ Pacific $=2.8 \%$; Hispanic $/$ Latino $=0.5 \%$; and Native American $=2.3 \%$; Other $=1.7 \%$ ).

The majority of respondents $(21 \%)$ have been employed at the university between 6 and 10 years and most $(26 \%)$ holds a Master's degree. Forty-one percent of these staff respondents work in academic affairs; 29\% work in finance and business affairs; $22 \%$ work in student affairs, with the remaining $8 \%$ working in university advancement. Most staff members (56\%) have positions that are unclassified; $30 \%$ are classified, non-bargaining positions; the remaining $14 \%$ are classified positions.

Most staff members work with supervisors who are White $(88 \%)$ and male $(60 \%)$. Similarly, most staff respondents' work units are predominantly White $(85 \%)$. In terms of gender composition, respondents indicate that $16 \%$ of their immediate work units are predominantly male, $46 \%$ are predominantly female, and $38 \%$ are balanced.

\section{Instrument}

The survey instrument used for this study was adapted from a diversity climate survey that was developed at the Higher Education Research Institute (HERI) at University of California at Los Angeles. HERI's survey was adapted from a diversity climate survey previously developed at university of California at Berkeley.

The survey questions have been tested over time and continue to hold content validity. Cronbach's alpha was used as a measure of reliability for a factor analysis designed to test how well the questions on the survey measured the particular constructs of the survey (e.g., experience with diversity, etc.); alpha levels for this instrument indicated that the survey was well within the limits of acceptable reliability, using standard statistical conventions.

In addition, the survey was adapted to reflect diversity-related concerns indigenous to this university. For example, a series of items were designed to measure the climate for diversity of the city in which the university is situated; staff were asked to indicate the degree to which they agreed with statements like, "XXX is a diverse community," and "XXX is a safe (i.e., crime-free) community." 
Moreover, in order to measure the different kinds of diversity represented on campus, questions were specifically asked about race, ethnicity, gender, religion and sexual orientation.

\section{Variables}

The dependent variable used in this study was a factor titled "achieved a positive climate for diversity." Potential independent variables and factors for the full model were organized under six constructs: staff demographics (i.e., gender, race, age, and education), staff professional characteristics (i.e., length of employment, job classification and job affiliation), local unit structural diversity, perceptions of department climate for diversity, perceptions of institutional commitment to diversity, and personal experiences with diversity. Table 1 presents an overview of variables used in this study.

\section{Analysis}

In order to reduce the number of measured variables used in the regression model, exploratory factor analyses were conducted, using principle axis factoring and orthogonal rotation methods. Factor loadings containing a score of at least 0.40 or higher were used in the development of subsequent summative scales. Internal validity for each of these scales was moderate to high, with Cronbach's alpha reliabilities ranging from 0.60 to 0.94 . One of these factors, "positive climate for diversity," $(\mathrm{M}=2.6, \mathrm{SD}=0.66)$, served as the criterion for the heierarchical regression analysis. See Table 2 for a complete description of the factors used in the final model for this study.

Multiple regression analyses were performed to determine how the factors work together to predict the criterion. Regression diagnostics confirmed that the assumptions of normality, linearity and homogeneity were met. A series of variables making up the demographics construct (i.e., gender, race) and the professional characteristic construct (i.e., job classification and job affiliation) were recoded for use in the regression model: gender $(0=$ male, $1=$ female $)$, race $(0=$ white, $1=$ staff of color $)$, job classification (dummy coded with unclassified positions serving as the reference group) and job affiliation (dummy coded with academic affairs serving as the reference group). In addition, two transformation procedures were performed on department structural diversity variables: gender of supervisor $(0=$ male, $1=$ female $)$ and race of supervisor $(0=$ white, $1=$ staff of color $)$. Unfortunately, we did not have adequate sample sizes to investigate subgroup differences (African-American, 


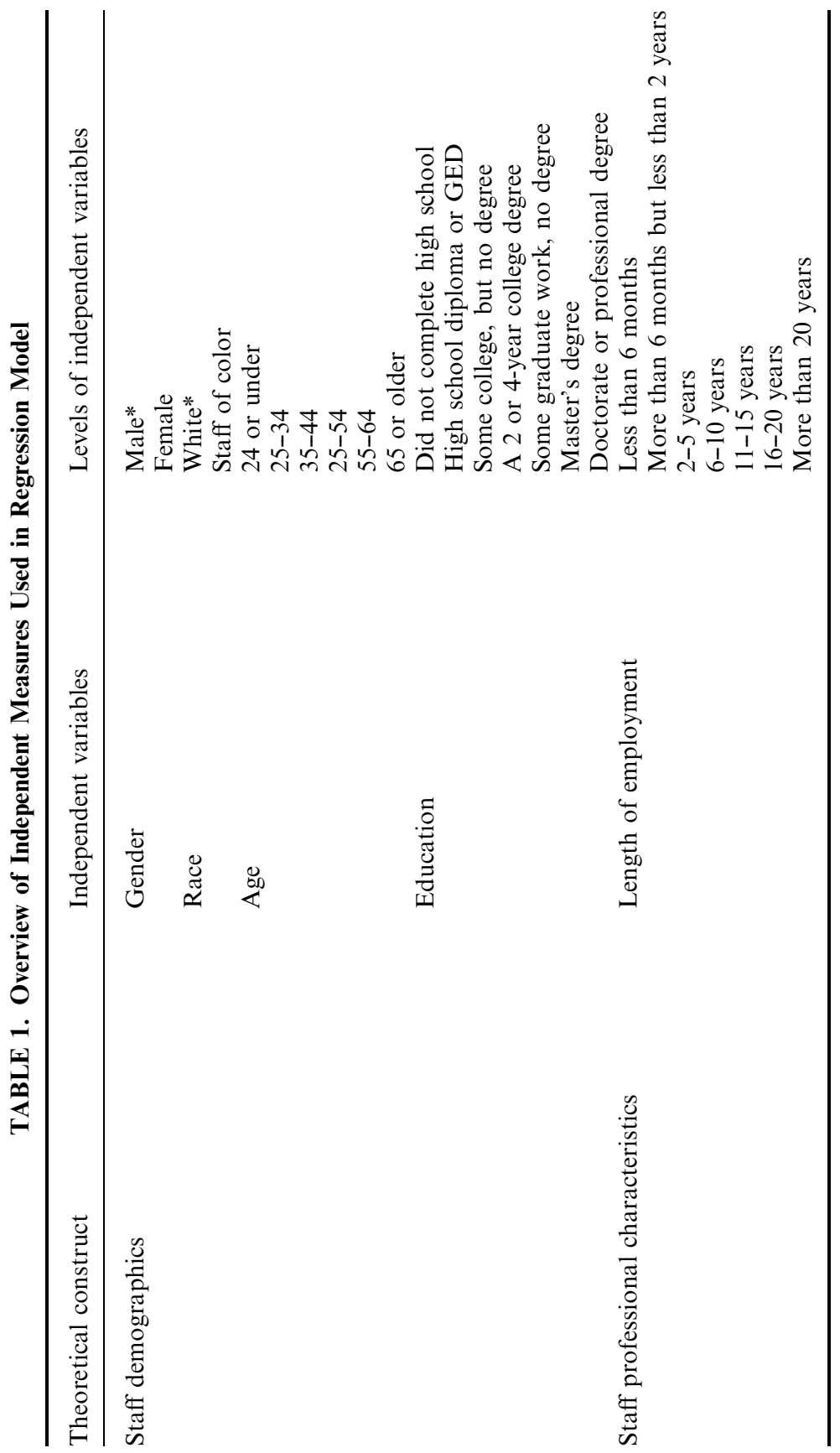




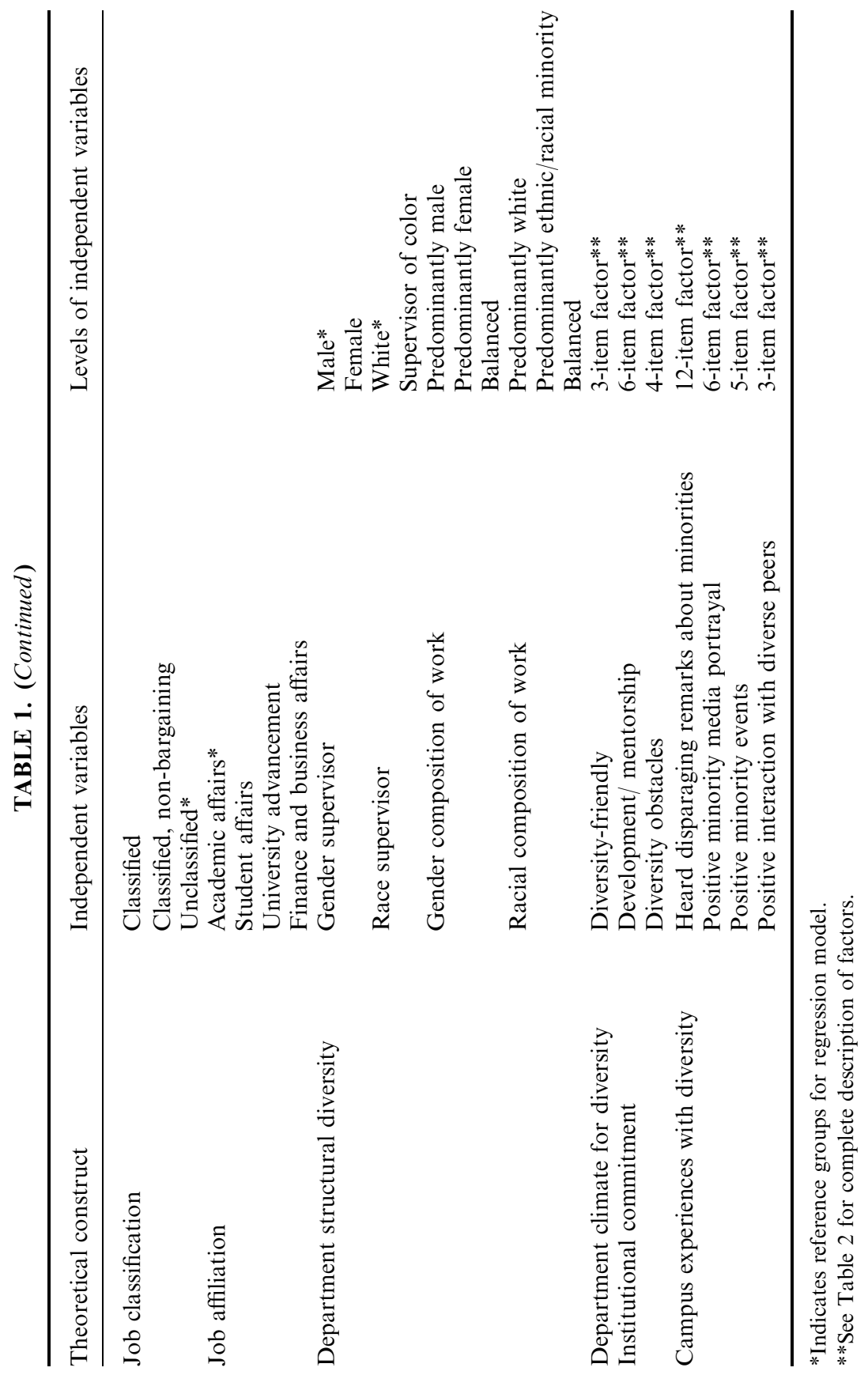




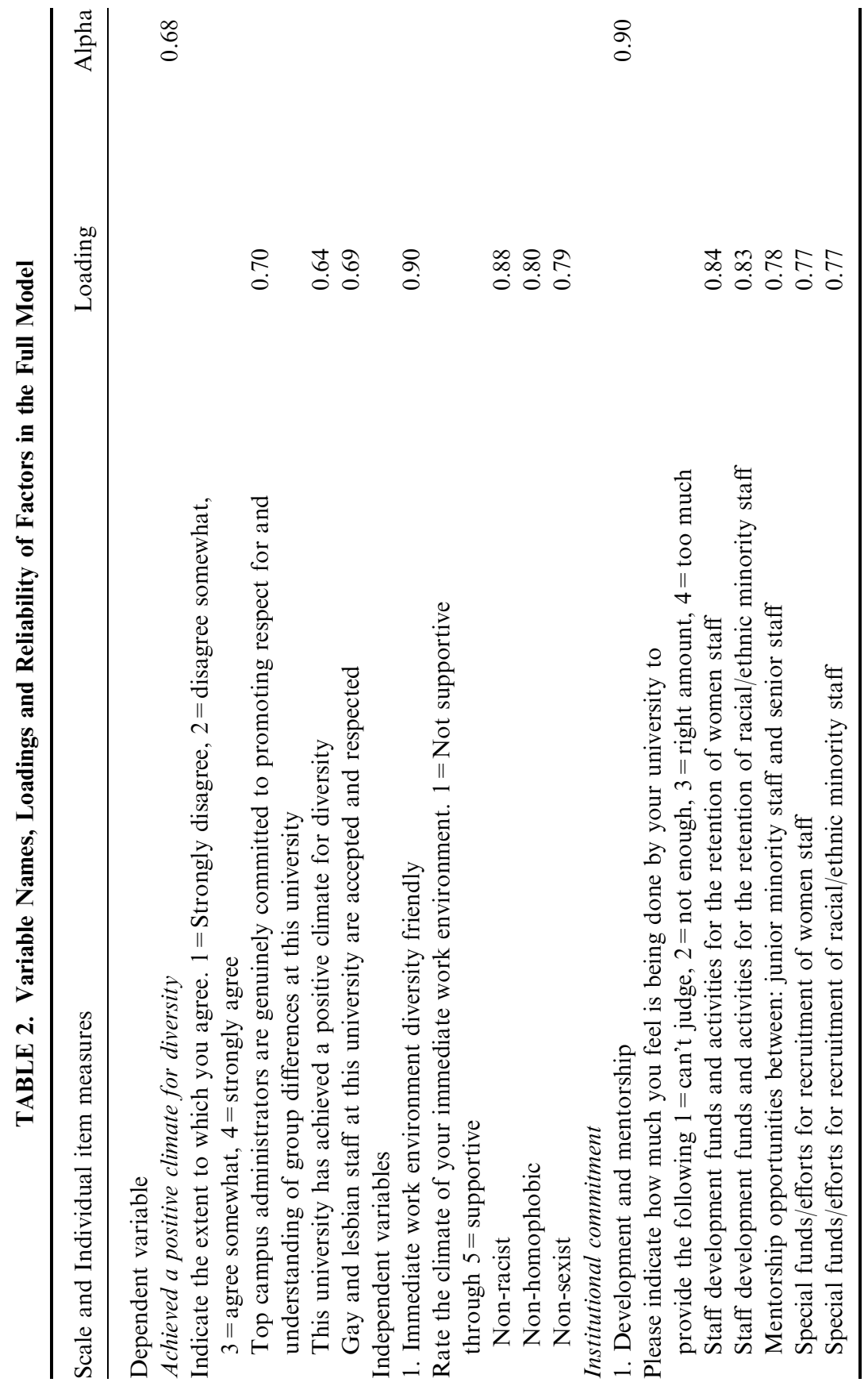




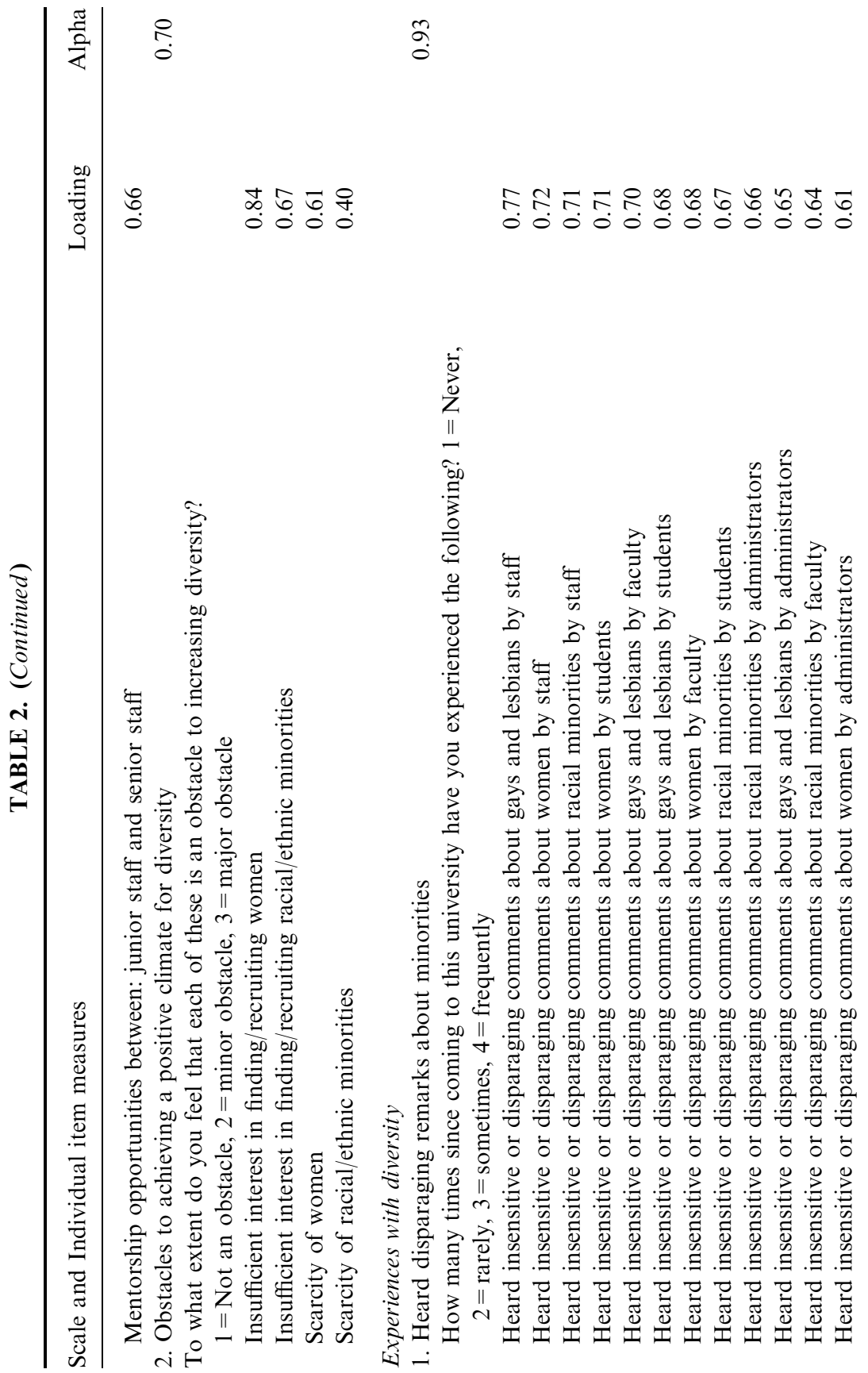


$\bar{\sigma}$

ț

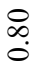

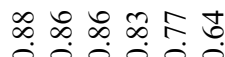

$\infty \infty \infty \frac{0}{\infty}$

슝

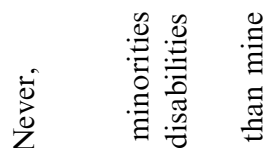

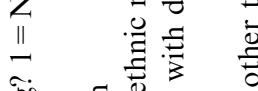

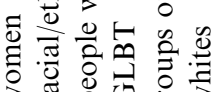

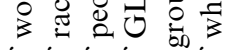

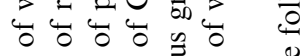

\& bo bo bo bo 0 b

00000

000

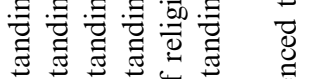

क्ञ心

过 它

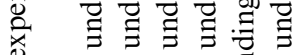

D D D D D

ᄀ.

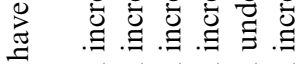

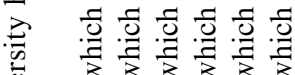

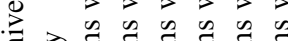

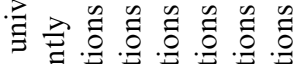

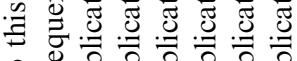

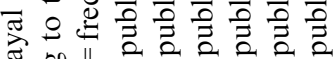

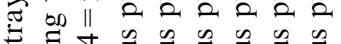

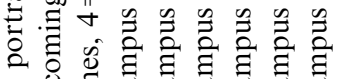

之.

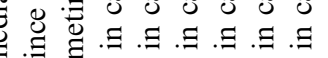

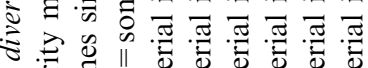

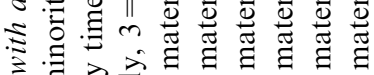

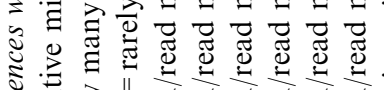

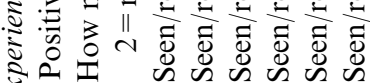

这

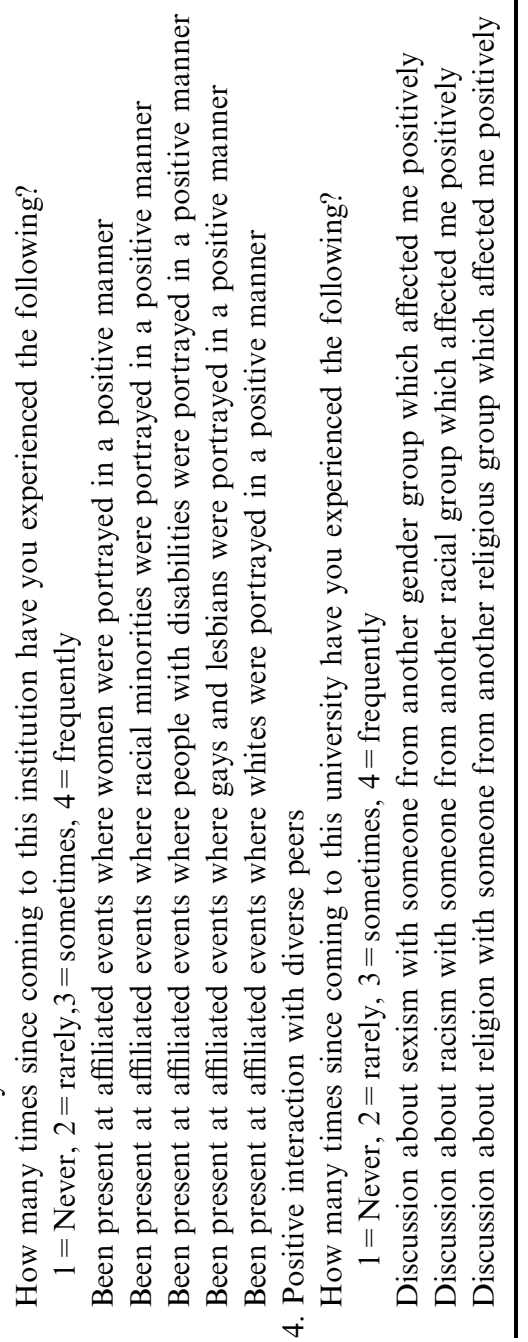


Hispanic/Latino, Native American, and Asian American, respectively) in perceptions and experiences of diversity on campus; for this reason, we had to use dichotomous variables for the race-related variables (i.e., race and race of supervisor) in the model.

A blocked hierarchical approach was used to add variables to the model. This process yielded a six-construct solution. Block 1 reflects information on staff demographic variables, including gender, race, age, and education level. Block 2 accounts for staff professional characteristics, such as length of employment, position classification, and department. Variables comprising Block 3 measure the structural diversity of staff members' department (i.e., gender of supervisor, race of supervisor, gender composition of work environment, and racial composition of work environment). Block 4 is made-up of a single item measuring the departmental climate for diversity. Block 5 includes variables that reflect the institutional commitment to diversity. Finally, variables that measure staff members' personal experiences with diversity (i.e., hearing disparaging remarks about diverse others, seeing diversity positively portrayed in the media and at minority events, and engaging in positive interactions with diverse peers) are organized as Block 6. See Table 3 for a complete description of the standardized regression coefficients for each variable used in the model.

\section{RESULTS}

The final model significantly predicts $34.7 \%$ of the variance in the criterion, "achieved a positive climate for diversity," $F(21,222)=6.625$. Four of the six blocks of variables (i.e., staff demographics, department climate for diversity, institutional commitment to diversity, and staff experiences with diversity) contributed significantly to explaining staff members' perceptions of their institutions as having achieved a positive climate for diversity.

\section{Staff Demographics}

The first block of variables measuring staff demographics significantly explains $10.9 \%$ of the variance in the criterion. Gender $(\beta=-0.29$, $p<0.001)$, level of education $(\beta=-0.18, p<0.01)$, and race $(\beta=-0.16$, $p<0.01)$ significantly predicted variance in the outcome. Females were significantly less likely than males to perceive that the campus community had achieved a positive climate for diversity. In addition, staff members with higher education levels were significantly less likely than staff with lower education levels to perceive the campus community as having 


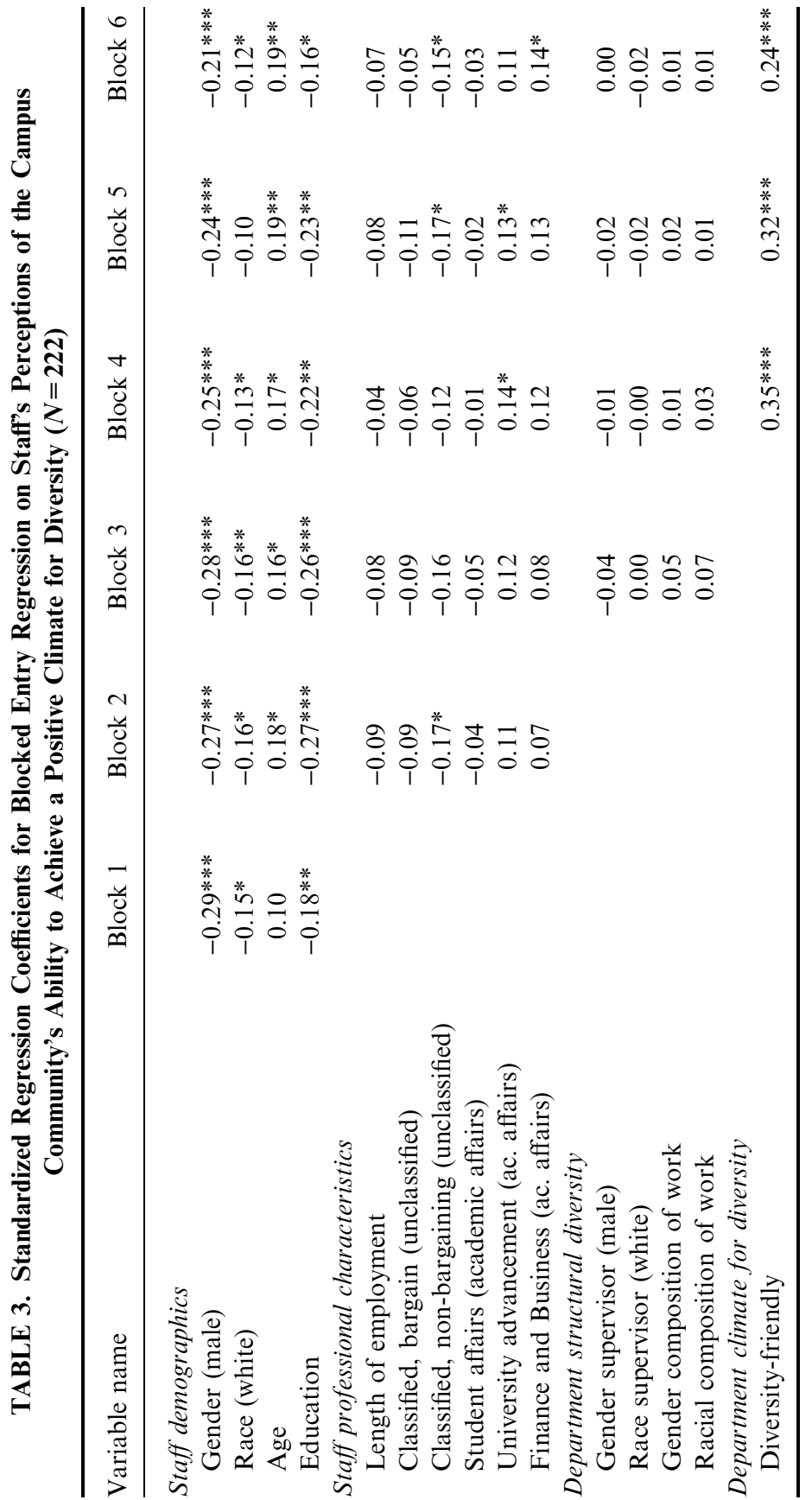




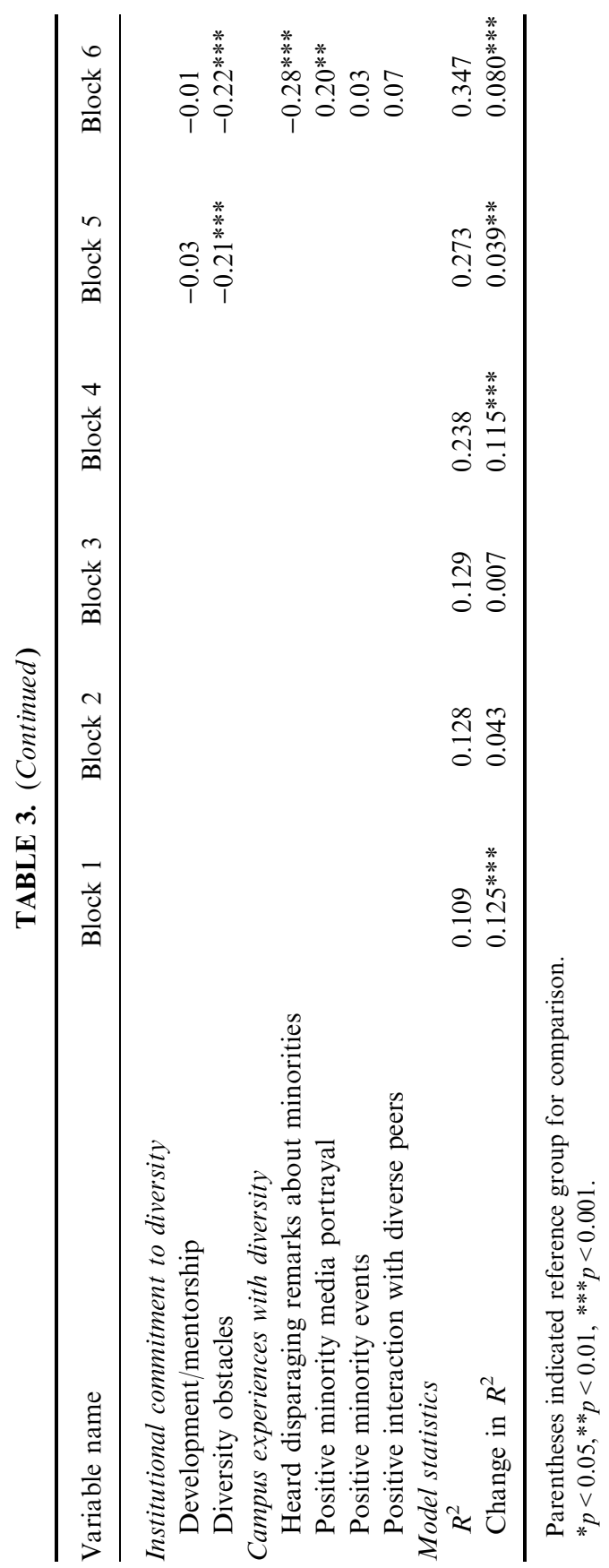


achieved a positive climate for diversity. Finally, staff members of color were less likely than white staff to perceive that the campus community had achieved a positive climate for diversity.

\section{Staff Professional Characteristics}

The second construct containing items that measure staff professional characteristics did not significantly contribute to explaining any variance in the outcome over and beyond staff demographics. In terms of professional characteristics, when compared to unclassified staff positions, staff members in classified, non-bargaining positions $(\beta=-0.17, p<0.05)$ were significantly less likely to perceive that the campus community had achieved a positive climate for diversity, after controlling for all other variables in the model.

Effects for gender, education level, and race remained significant after adding the second block of variables. In addition, age $(\beta=-0.18$, $p<0.05)$ became significant after adding professional characteristics into the model; this indicates that older staff members are significantly more likely to perceive the campus community as having achieved a positive climate for diversity than younger staff members.

\section{Department Structural Diversity}

Controlling for staff demographics and professional characteristics, the block of variables that included measures of the department's commitment to structural diversity yielded no significant predictors. Adding this set of four variables (i.e., the gender of the supervisor, race of the supervisor, gender composition of the local unit, and racial composition of the local unit) only helped to explain an extra $0.7 \%$ of the variance over and beyond staff demographic and professional characteristic variables.

However, when these variables were added to the model, position classification dropped out of significance. Education level, gender, age, and race remained statistically significant.

\section{Department Climate for Diversity}

Controlling for staff demographics, professional characteristics, and measures of department structural diversity, department climate for diversity significantly explained an additional $11.5 \%$ of the variance in the criterion. Staff members working in diversity-friendly (non-racist, non-sexist, non-homophobic environments) climates $(\beta=0.35$, $p<0.001)$ were significantly more likely to perceive that the campus 
community had achieved a positive climate for diversity than were staff members working in diversity-unfriendly environments.

After adding this factor, education level, gender, age, and race remained statistically significant. However, adding this factor to the model had an effect on one job affiliation variable, namely University Advancement. When compared to positions in Academic Affairs, staff members who held positions in University Advancement $(\beta=0.14$, $p<0.05)$ were significantly more likely to perceive that the campus community had achieved a positive climate for diversity.

\section{Institutional Commitment to Diversity}

Controlling for staff demographics, professional characteristics, measures of department structural diversity, and perception of the department's climate for diversity, variables comprising the institutional commitment construct significantly explained an additional $3.9 \%$ of the variance in the criterion. Specifically, staff members' perceptions of obstacles towards achieving diversity at the institutional level $(\beta=-0.21$, $p<0.001)$ significantly influenced their perceptions of the campus community as having achieved a positive climate for diversity. In other words, staff members who were more likely to perceive that there were major institutional obstacles (i.e., scarcity of qualified women and minorities, and insufficient interest in funding and recruiting women and minorities) to increasing diversity on campus were less likely to perceive that their community's had achieved a positive climate for diversity.

Consistent with other findings, level of education, gender, and age remained statistically significant predictors of the criterion, after adding institutional commitment variables to the model. Similarly, after adding institutional commitment variables, staff members who perceived their departments as diversity-friendly were still more likely to perceive that their community had achieved a positive climate for diversity $(p<0.001)$. Moreover, when compared to staff members in Academic Affairs, the relationship between University Planning and the campus community's ability to achieve a positive climate for diversity remained significant.

However, adding the institutional commitment construct to the other constructs affected race by bringing it to a marginally significant level, $(\beta=-0.10, p<0.10)$. This suggests a possible suppressor effect; the race of the staff member and their perceptions of the institutional commitment to diversity may be so closely connected that adding institutional commitment to diversity to the model might be explaining the same proportion of the variance as the race variable. 
Moreover, adding the "institutional commitment" construct brought job classification back into significance. When compared to unclassified staff positions, staff members in classified, non-bargaining positions $(\beta=-0.17, p<0.05)$ were significantly less likely to perceive that the campus community had achieved a positive climate for diversity, after controlling for all other variables in the model.

\section{Campus Experiences with Diversity}

Controlling for staff demographics, department structural diversity, perception of the department's climate for diversity, and perceptions of the institution's commitment to diversity, factors comprising the "campus experiences with diversity" construct significantly explained an additional $8.0 \%$ of the variance in the criterion. Specifically, staff members who were more likely to have heard disparaging remarks about a marginalized group $(\beta=-0.28, p<0.001)$ were less likely to perceive their community as having achieved a positive climate for diversity. In addition, staff members who were more likely to have seen minorities portrayed positively in campus media were also more likely to perceive that their community had achieved a positive climate for diversity $(\beta=0.20, p<0.01)$.

Education level, gender, age, classified non-bargaining staff positions, perceptions of departments as diversity-friendly, and perceptions of institutional obstacles toward increasing diversity remained significant predictors of the criterion, after adding variables that comprised the "campus experiences with diversity" construct.

Interestingly, after adding this construct, race $(\beta=-0.12, p<0.05)$ reached statistical significance. Similarly, when compared to positions in academic affairs, staff members who hold positions in Finance and Business $(\beta=0.14, p<0.05)$ were significantly more likely to perceive that the campus community had achieved a positive climate for diversity, after controlling for all other variables in the model.

\section{Subsequent Analyses}

Results from this regression analysis indicated strong gender and race effects across most iterations of the six-block model under investigation for this study. For this reason, we performed other regression analyses that included interaction terms for gender and race with every other predictor in the model. None of these interaction terms significantly predicted variance in the outcome. 


\section{Limitations}

The dearth of theory and literature investigating staff members' perceptions of their institutional climate for diversity impeded our ability to make a priori judgments about the nature and directionality of the relationships between the constructs used in this study. In addition, the sample was not weighted for non-response bias because demographic data could not obtained for non-responders. After repeated attempts, we could not attain institutional records concerning the demographic profiles (gender, race, department) of campus staff members; as such, we were unable to compare demographic variables from our analytic sample with those of overall staff community on this campus. This limitation may bias the sample, and renders it difficult to ascertain the impact of such bias on the results of the study.

Moreover, earlier research suggests that people from different racial and ethnic groups experience the climate in very different ways. Lack of sufficient sample sizes precluded us from comparing perceptions across racial and ethnic groups. As such, we dichotomized the race variable into two groups: staff of color and white staff. Future research in this area should correct for this limitation by adopting more robust sampling strategies.

Finally, although the variable to case ratio is acceptable using standard statistical conventions, it is marginal with a sample of 222 staff and 21 variables under investigation. Findings should be interpreted accordingly.

\section{DISCUSSION}

Institutional researchers need to account for many factors when trying to predict staffs' perceptions of their campus' climate for diversity. Six constructs were identified as potential determinants of these perceptions; among these were personal demographics, professional characteristics, department structural diversity, perceptions of department climate for diversity, perceptions of the institution's commitment to diversity, and personal experiences with diversity. Collectively, these constructs explained $35 \%$ of the variance in staff's perceptions of their institution's success in achieving a positive climate for diversity. It is important for institutional leaders to understand that staff perceptions are influenced by a wide variety of factors, ranging from previous experiences with diversity to recent on-campus experiences with prejudice and discrimination. More importantly, institutional leaders need to understand that staff perceptions can be influenced; institutional leaders have the power 
to be effective agents for changing staff members' opinions about the role and value of diversity on campus.

How can these perceptions be influenced? Current findings suggest that media, either spoken or written, exerted significant influence on staff member's perceptions of the campus community as having achieved a positive climate for diversity. Specifically, written materials that positioned issues of diversity in a positive light had a positive effect on staff members' perceptions of the community's success in achieving a positive climate for diversity. Inversely, hearing disparaging remarks about minorities had negative effects. This pattern underscores the importance of developing and maintaining a positive campus environment that welcomes and encourages communication around diversity-related issues (Hurtado and Dey, 1997; Hurtado et al., 1998).

It is also important to understand that communication and the subsequent meaning that individuals ascribe to the communicated message occurs within context. In order to understand the impact of these messages upon perceptions, it is imperative to understand the context in which the messages are given and received. One such context is the department in which the staff members work on a day-to-day basis. Until now, most research on understanding diversity contexts has focused primarily on climates for diversity at the institutional level (Hurtado et al., 1998) and at the classroom level (Gurin, Dey, Hurtado, and Gurin, 2002). This study emphasizes the importance of understanding how a department's climate for diversity affects perceptions of the campus community's success in achieving a positive climate for diversity. Specifically, staff members who perceived their local unit to be non-sexist, non-racist, and non-homophobic were consistently more likely to perceive that their community had achieved a positive climate for diversity. This finding is consistent with organizational literature that underscores the importance of identifying departmental factors and accounting for their roles on influencing perceptions of institutional climate (Lindholm, 2003; Mayhew and Grunwald, in press; Petersen, 1976), as well as the common phrase about environmental concerns: think globally, act locally.

How an institution represents its commitment to diversity is also an important consideration for researchers interested in understanding how staff members perceive their institution's climate for diversity. Staff members who were more likely to perceive that there were major institutional obstacles (i.e., scarcity of qualified women and minorities, and insufficient interest in funding and recruiting women and minorities) to increasing diversity on campus were also more likely to perceive that their communities had not achieved a positive climate for diversity. 
Interestingly, these obstacles reflect an institution's commitment to improving the campus' structural diversity, the numerical and proportional representation of diverse groups on campus. This finding is intriguing, especially in light of findings concerning the lack of significant effects of a department's structural diversity on perceptions of institutional climate. Perhaps, the impact of structural diversity on staff perceptions of the campus community's ability to achieve a positive climate for diversity occurs at the institutional level, while the impact of psychological climate on these same perceptions occur at the department level. Future research is needed to untangle the roles of different contextual effects on staff perceptions of a community as having achieved a positive climate for diversity.

The results of this study indicate that there are important demographic differences amongst the views of postsecondary staff members at the institution examined. The finding that perceptions vary as a function of race and gender is consistent with those based on studies of populations more commonly studied by diversity researchers (e.g., students and faculty), indicating some degree of commonality (Dey, 1993; Hurtado et al., 1998; Mayhew and Grunwald, in press; Mayhew, Grunwald, and Dey, in press; Nora and Cabrera, 1996). When compared to men, women are more critical of their institutions as having achieved a positive climate for diversity. Similar patterns hold for staff of color; when compared to white staff, staff members of color have more negative perceptions of the campus community's success in achieving a positive climate for diversity. Hurtado et al. (1998) attribute this finding to the power and positionality that are frequently associated with race and gender: "who you are and where you are positioned in an institution will affect how you experience and view the institution" (p. 290).

People from historically marginalized groups adopt a more critical view of issues related to diversity than people from more traditional social identity groups (Hurtado, Dey, and Trevino, 1994; Nora and Cabrera, 1996). The idea of a "critical approach" to campus diversity issues is supported by other findings from this study. Staff members with higher levels of education are more likely to perceive their community as not having achieved a positive climate for diversity. Perhaps, highly educated staff members are more aware and sensitive to issues of diversity on campus. This heightened awareness and sensitivity may give them the tools needed to make critical and informed judgments about the campus and its community's success in achieving a positive climate for diversity. 


\section{CONCLUSION}

Comprehensive assessments of campus climates for diversity need to include voices from all members of the "institution's" community. By excluding staff from institutional research efforts designed to assess a campus' climate for diversity, researchers may fail to capture certain nuances of discrimination and prejudice that exist in contexts outside of the classroom but which have great implications for institutional effectiveness (Cox, 2001).

For future research, these results suggest the need for further development and refinement of theoretical models and research designs used to study diversity-related issues on campus. In terms of theoretical development, there continues to be a need to merge theoretical models used in the organizational literature with those in the higher education literature; integrating theory from these schools of thought may provide critical insight into the role that organizational dynamics, such as person-environmental fit (Caplan, 1987; Kristof, 1996; Muchinsky and Monahan, 1987) play in addressing issues related to diversity on campus. For example, work by Berger and Milem (2000) examining the interconnections between organizational behavior theory and student outcomes could serve as model for approaching ways to understand staff within higher education settings.

In terms of theoretical refinement, there remains a need to untangle the factors identified for use in this study. To this end, we recommend using more qualitative techniques; this will enable researchers is answer questions related to how certain experiences with prejudice and discrimination affect perceptions of the institution's and department's commitments to diversity and how these experiences and perceptions shape the campus community's overall ability to achieve a positive climate for diversity. From a research design perspective, future research should deploy design strategies with adequate sample sizes to explain subgroup differences (e.g., race, race by gender interactions) in perceptions and experiences of diversity on campus. In addition, the ability to clearly model departmental and institutional effects using more sophisticated analytical techniques, such as hierarchical linear modeling, would also be a fruitful addition to work in this area.

For institutional planners to be successful in procuring and maintaining staff engagement in diversity-related reform efforts, they need to consistently emphasize the campus climate for diversity as an institutional priority. For staff, this emphasis needs to be reflected in tangible ways, namely through the proliferation of campus media designed to increase 
awareness about marginalized groups and through increased visibility of these groups on campus.

In addition, institutional planning and management teams need to establish clear guidelines for reporting instances of hate-speech across campuses. Rigorous steps need to be taken to communicate these guidelines to all members of the campus community. Hopefully, this might reduce the number of disparaging remarks heard by staff from different constituencies across campus, and subsequently increase their perceptions of the campus community as having achieved a positive climate for diversity.

Departments may be effective contexts for communicating these guidelines. When enacting change, institutional planning and management teams from large universities should investigate how issues of diversity and perceptions of diversity vary by department or local unit. This will ameliorate efforts intentionally designed to reach targeted community members by focusing on their specific needs and issues pertaining to raising diversity awareness and sensitivities. Whatever the strategy, it is important for institutional managers to exhaust all means necessary to impress upon staff members the urgency and seriousness of the diversity-related reform effort at hand.

\section{REFERENCES}

Association of American Colleges and Universities. (1998). Diversity blueprint: A planning manual for colleges and universities. ERIC Digest, ED430440.

Baker, T.L. (1999). Safe harbor: Helping faculty and staff become allies to students who need support. ERIC Digest, ED435870.

Berger, J. B., and Milem, J. F. (2000). Organizational behavior in higher education and student outcomes. In: Smart, J. C. (ed.) Higher Education: Handbook of Theory and Research Volume $X V$, Agathon Press, New York, pp. 268-338.

Berkeley, T. R. (1997). A focus on diversity and change: Professional development, partnership, and commitment. ERIC Digest, ED405339.

Birnbaum, R. (1988). How Colleges Work: The Cybergenetics of Academic Organization and Leadership, (2nd Ed.) Jossey-Bass, San Francisco.

Bolman, L. G., and Deal, T. E (1997). Reframing Organizations: Artistry, Choice, and Leadership, (2nd Ed.) Jossey-Bass, San Francisco.

Caplan, R. D. (1987). Person-environment fit theory and organizations: Commensurate dimensions, time perspectives, and mechanisms. Journal of Vocational Behavior 31: 248-267.

Chang, M. J. (2002). The impact of an undergraduate diversity course requirement on students' racial views and attitudes. The Journal of General Education 51(1): 21-42.

Cox, T. H. (1993). Cultural Diversity in Organizations: Theory, Research and Practice, BerrettKoehler, San Francisco.

Cox, T. H. (2001). Creating the Multicultural Organization: A Strategy for Capturing the Power of Diversity, Jossey-Bass, San Francisco. 
Cox, T. H., and Blake, S. (1991). Managing cultural diversity: Implications for organizational competitiveness. The Executive 5(3): 45-56.

Dey, E. L. (1993). Perceptions of the College Environment: An Analysis of Student and Faculty Differences. Paper presented at the Association for Institutional Research, Chicago, IL.

Fortune 500 Companies. (2003). Amicus brief in Filed with the Sixth Circuit Court of Appeals in Gratz v. Bollinger. Retrieved from the Internet October 20, 2003, at http:// www.umich.edu/ urel/admissions/legal/gra_amicus/index.html.

General Motors Corporation. (2003). Amicus brief in Filed with the Sixth Circuit Court of Appeals in Gratz v. Bollinger. Retrieved from the Internet October 20, 2003, at http:// www.umich.edu/ urel/admissions/legal/gra_amicus/index.html.

Growe, R., Schmersahl, K., Perry, R., and Henry, R. (2001). Diversity education in administrator training: Preparation for the 21st century. ERIC Digest, ED457548.

Gurin, P., Dey, E. L., Hurtado, S., and and Gurin, G. (2002). Diversity and higher education: Theory and impact on student outcomes. Harvard Educational Review 72(3): 330-366.

Horton, H. W. (2000). Perspectives on the current status of the racial climate relative to students, staff, and faculty of color at predominantly white colleges and universities in America. Equity and Excellence in Education 33(3): 35-37.

Howard-Hamilton, M. F., Phelps, R. E., and Torres, V. (1998). Meeting the needs of all Students and Staff members: The challenge for diversity. New Directions for Students Services 82: 49-64.

Hurtado, S. (2001). Linking diversity and educational purpose: How diversity affects the classroom environment and student development. In: Orfield, G. (eds.), Diversity Challenged: Evidence on the Impact of Affirmative Action, Education Publishing Group, Cambridge, Harvard, pp. 187-203.

Hurtado, S., Dey, E. L., and Trevino, J. (1994). Exclusion of Self-segregation? Interaction across Racial/Ethnic Groups on College Campuses. Paper presented at the American Educational Research Association, New Orleans.

Hurtado, S., and Dey, E. L. (1997). Achieving the goals of multiculturalism and diversity. In: Peterson, M., Dill, D., Mets, L., and Associates (Eds.), Planning and Management for a Changing Environment, Jossey-Bass, San Francisco, pp. 405-431).

Hurtado, S., Milem, J. F., Clayton-Pedersen, A. R., and Allen, W. (1998). Enhancing campus climates for racial/ethnic diversity: Educational policy and practice. The Review of Higher Education 21(3): 279-302.

Kellogg, K. (1999). Collaboration: Student affairs and academic affairs working together to promote student leaning. ERIC Digest, ED432940.

Kristof, A. L. (1996). Person-organization fit: An integrative review of its conceptualizations, measurement, and implications. Personnel Psychology 49(1): 1-49.

Lindholm, J. A. (2003). Perceived organizational fit: Nurturing the minds, hears, and personal ambitions of university faculty. The Review of Higher Education 27(1): 125-149.

Marcus, L. R. (2000). Staff diversity and the leadership challenge. Equity and Excellence in Education 33(2): 61-67.

Maruyama, G., Moreno, J. F., Harvey, J., Gudeman, R. H., and Marin, P. (2000). Does Diversity make a Difference? Three Research Studies on Diversity in College Classrooms, American Council on Education, Washington D.C. http://www.acenet.edu.

Mayhew, M. J. and Grunwald, H. E. (in press). Factors that contribute to faculty's incorporation of diversity-related content into their course materials. Journal of Higher Education.

Mayhew, M. J., Grunwald, H. E., and Dey, E. L. (2005). Curriculum matters: Creating a positive climate for diversity from the student perspective. Research in Higher Education 46(4): 389-412. 
Milem, J. P. (2001). Increasing diversity benefits: How campus climate and teaching methods affects student outcomes. In: Orfield, G. (eds.), Diversity Challenged: Evidence on the Impact of Affirmative Action, Education Publishing Group, Cambridge Harvard, pp. 233-249.

Muchinsky, P. M., and Monahan, C. J. (1987). What is person-environment congruence? Supplementary versus complementary models of fit. Journal of Vocational Behavior 31: 268277.

Nora, A., and Cabrera, A. F. (1996). The role of perceptions of prejudice and discrimination on the adjustment of minority students to college. Journal of Higher Education 67(2): 119-148.

Peterson, M. W. (1976). The academic department: Perspectives from theory and research. In: Kerlinger, F. N., and Carroll, J. B. (eds.), Examining Departmental Management: New Directions for Institutional Research, Vol. 10. JAI, Greenwich, CT, pp. 21-38.

Peterson, M. W., and Spencer, M. G. (1990). Understanding academic culture and climate. In: Peterson, M. W., Chaffee, E. E., and White, T. H. (eds.), ASHE Reader on Organization and Governance in Higher Education, 4th edition, Simon and Schuster Custom Publishing, Needham Heights, MA, pp. 140-152 (Reprinted from New Directions for Institutional Research, no. 68, 1990).

Sanchez, W. (1995). Working with diverse learners and school staff in a multicultural society. ERIC Digest, ED390018.

Walters, E. (2002). Commitment to diversity and multiculturalism through institutional transformation: A case study of Olivet College. Journal of College Student Retention 3(4): 333-350.

Received January 7, 2004. 